\title{
Financial Stressors as Catalysts for Relational Growth: Bonadaptation Among Lower-Income, Unmarried Couples
}

\author{
Ashley B. LeBaron \\ University of Arizona \\ Melissa A. Curran \\ University of Arizona \\ Xiomin Li \\ University of Arizona \\ Jeffrey P. Dew \\ Brigham Young University - Provo, jeff_dew@byu.edu \\ Trevor K. Sharp \\ Follow this and additional works at: https://scholarsarchive.byu.edu/facpub \\ Part of the Other Social and Behavioral Sciences Commons \\ See next page for additional authors

\section{Original Publication Citation} \\ LeBaron, A. B.*, Curran, M. A., Li, X., Dew, J. P., Sharp, T. K.†, \& Barnett, M. A. (2020). Financial \\ stressors as catalysts for relational growth: Bonadaptation among lower-income, unmarried \\ couples. Journal of Family and Economic Issues.
}

\section{BYU ScholarsArchive Citation}

LeBaron, Ashley B.; Curran, Melissa A.; Li, Xiomin; Dew, Jeffrey P.; Sharp, Trevor K.; and Barnett, Melissa A., "Financial Stressors as Catalysts for Relational Growth: Bonadaptation Among Lower-Income, Unmarried Couples" (2020). Faculty Publications. 4543.

https://scholarsarchive.byu.edu/facpub/4543

This Peer-Reviewed Article is brought to you for free and open access by BYU ScholarsArchive. It has been accepted for inclusion in Faculty Publications by an authorized administrator of BYU ScholarsArchive. For more information, please contact ellen_amatangelo@byu.edu. 
Authors

Ashley B. LeBaron, Melissa A. Curran, Xiomin Li, Jeffrey P. Dew, Trevor K. Sharp, and Melissa A. Barnett 


\title{
Financial Stressors as Catalysts for Relational Growth: Bonadaptation Among Lower-Income, Unmarried Couples
}

\author{
Ashley B. LeBaron ${ }^{4}$ (1) $\cdot$ Melissa A. Curran ${ }^{1} \cdot{\text { Xiaomin } \mathrm{Li}^{1} \cdot \text { Jeffrey P. Dew }}^{2} \cdot$ Trevor K. Sharp $^{3} \cdot$ Melissa A. Barnett $^{1}$
}

Published online: 5 February 2020

(c) Springer Science+Business Media, LLC, part of Springer Nature 2020

\begin{abstract}
The FAAR model (Patterson in Fam Syst Med 6(2):202-237, 1988) posits that following a stressor, demands, capabilities, and meanings can contribute to bonadaptation (i.e., adaptation that promotes wellbeing). The purpose of the current study is to test how financial and relational demands, capabilities, and meanings are associated with relationship commitment and coparenting (i.e., bonadaptation) following a financial stressor. We used data from the Building Strong Families (BSF) sample (i.e., primarily lower-income, unmarried couples; $\mathrm{N}=1396$ ). First, results showed that predictors of coparenting were more numerous than predictors of commitment. Second, all facets of the FAAR model—demands, capabilities, and meanings-were evident as predictors of bonadaptation. Finally, comparing the results with the results of a previous paper (i.e., a nationally-representative sample of married couples; Dew et al. in J Fam Econ Issues 39(3):405-421, 2018), relationship maintenance behaviors and financial support were capabilities for both samples, whereas other capabilities and meanings were context-specific (e.g., relational support significant in Dew et al. sample but not BSF sample). These patterns suggest that although some of the avenues to bonadaptation may differ depending on the sample, it is possible for couples to thrive not just in spite of financial stressors but even because of them; that is, financial stressors can serve as catalysts for positive relational growth.
\end{abstract}

Keywords Bonadaptation $\cdot$ Commitment $\cdot$ Coparenting $\cdot$ Financial stress $\cdot$ FAAR model

Patterson's (1988) family adjustment and adaptation response (FAAR) model built on an important concept in the family stress literature: bonadaptation (i.e., adaptation that promotes wellbeing). The possibility of bonadaptation following a stressor suggests that individuals, couples, and families can thrive not just in spite of stressors, but because of them. Stressors can act as catalysts for positive growth. Evidence of bonadaptation has been found in multiple studies (Campbell and Demi 2000; Kapp and Brown 2011). Although the FAAR model was originally constructed for family-level adaptation (Patterson 1988), evidence of

Ashley B. LeBaron

lebaronashley@gmail.com

1 University of Arizona, Tucson, AZ, USA

2 Brigham Young University, Provo, UT, USA

3 Deseret Mutual Benefit Association, Salt Lake City, UT, USA

4 University of Arizona, 650 N Park Ave, McClelland Park Room 401, Tucson, AZ 85721-0078, USA bonadaptation has been found in applying the FAAR model to couple-level research (Dew et al. 2018; Kelley et al. 2018). While bonadaptation does not suggest that couples should seek out stressors, it provides alternative ways to conceptualize stressors for couples who encounter stressors and for those who work with such couples.

Dew et al. (2018) examined predictors of relational bonadaptation (measured as perceived increased relationship commitment) following the 2007-2009 Recession. They used a nationally representative sample of primarily middle- to higher-income, married couples in the US $(N=1362)$ to examine how it was possible for couples' marriages to thrive because of, rather than in spite of, financial stressors. Following again from the FAAR model (Patterson 1988), the current study builds off of Dew et al.'s findings by using the Building Strong Families (BSF) dataset-primarily lower-income, unmarried partners experiencing a transition to parenthood $(N=1396$ U.S. couples) - to examine not only relationship commitment as a measure of bonadaptation but also coparenting as an additional measure of bonadaptation. Studying 
bonadaptation after a financial stressor among a different set of couples (i.e., primarily lower-income, unmarried couples) allows researchers to test the generalizability of the FAAR model outside of primarily middle- to higherincome, married couples. Identifying potential predictors of bonadaptation for lower-income, unmarried couples may be especially important given that financial stressors may occur more frequently and potentially have more negative consequences for these couples (e.g., negatively affect savings and credit, increase distress; Prawitz et al. 2013).

\section{The Family Adjustment and Adaptation Response (FAAR) Model}

The FAAR model describes the relationships among demands (including stressors), capabilities, and meanings. All couples experience stressors (Patterson 1988). A stressor may be defined as "a life event that occurs at a discrete point in time and produces, or has the potential of producing, change in the family social system" (Patterson 1988, p. 210). A stressor is a specific type of demand, "a stimulus or condition that produces or calls for change in the family system" (p. 210). The FAAR model (Patterson 1988) proposes that following a stressor event, couples must adjust and adapt to reobtain an equilibrium wherein demands and capabilities are in balance. As a complement to demands, a capability is "a potentiality the family has available to it for meeting demands" (p. 215). Capabilities include both resources (i.e., "what the family has", p. 215 ) and coping behaviors (i.e., "what the family does", p. 215). Couples also ascribe meanings, subjective perceptions, to their circumstances and relationships. "The family's subjective definitions of their demands, their capabilities, and of these two factors relative to each other" are situational meanings (pp. 220-221). Couple outcomes vary across the demands couples face, the capabilities they can draw upon to meet those demands, and the meanings they give both the demands and the capabilities.

Following a stressor, couples can either achieve maladaptation (i.e., adaptation that compromises wellbeing) or bonadaptation (i.e., adaptation that promotes wellbeing) (Patterson 1988). Here, we focused on relational bonadaptation following a financial stressor. Relational bonadaptation was operationalized as high relationship commitment and high coparenting after experiencing a financial stressor. As predictors, we examined the roles of financial demands, financial and relational capabilities, and financial and relational meanings in predicting relational bonadaptation.

\section{Bonadaptation Among a Nationally-Representative Sample of Married Couples}

Using data from married couples, Dew et al. (2018) examined whether and how the stressors of the 2007-2009 Recession related to the likelihood that participants would endorse the statement that, "The recession has deepened my commitment ${ }^{1}$ to my marriage." These scholars used the FAAR model (Patterson 1988) to frame their study. They posited that the financial stressors of the recession were "demands", the joint experience of the stressors and feelings of economic pressure were "meanings", and couples' financial/relationship resources and behaviors were "capabilities." Examples of capabilities from this study were financial assets, positive relationship behaviors, and religious capabilities.

From Dew et al., both wives' and husbands' perceptions that the recession directly stressed their marriage (i.e., meanings) were positively associated with reporting increased commitment. In line with the FAAR model, working together through a perceived marital threat allowed for bonadaptation. Further, many of the capabilities from Dew et al. were also associated with bonadaptation, including relationship maintenance behaviors (i.e., the daily "small things" that individuals do for their spouse). Other capabilities positively associated with relational bonadaptation were marital sanctification, social support for the marriage from one's network of family and friends, and receiving financial support from one's social network. It is of note that Dew et al. found no significant partner effects, meaning that only an individual's own characteristics and perceptions, and not those characteristics or perceptions of their spouse, were related to their self-reports of commitment.

\section{Generalizability}

Our study seeks to test whether the findings of Dew et al. (2018) apply to other populations; can the findings from Dew et al. be generalized to samples other than nationally representative, married couples-in particular, lowerincome, unmarried couples? In recent decades in the US,

\footnotetext{
1 Triangulating with some of the other variables in the sample suggested that participants were responding to this question more in the context of dedication, and not constraint, commitment (Dew et al. 2018; Stanley and Markman 1992).
} 


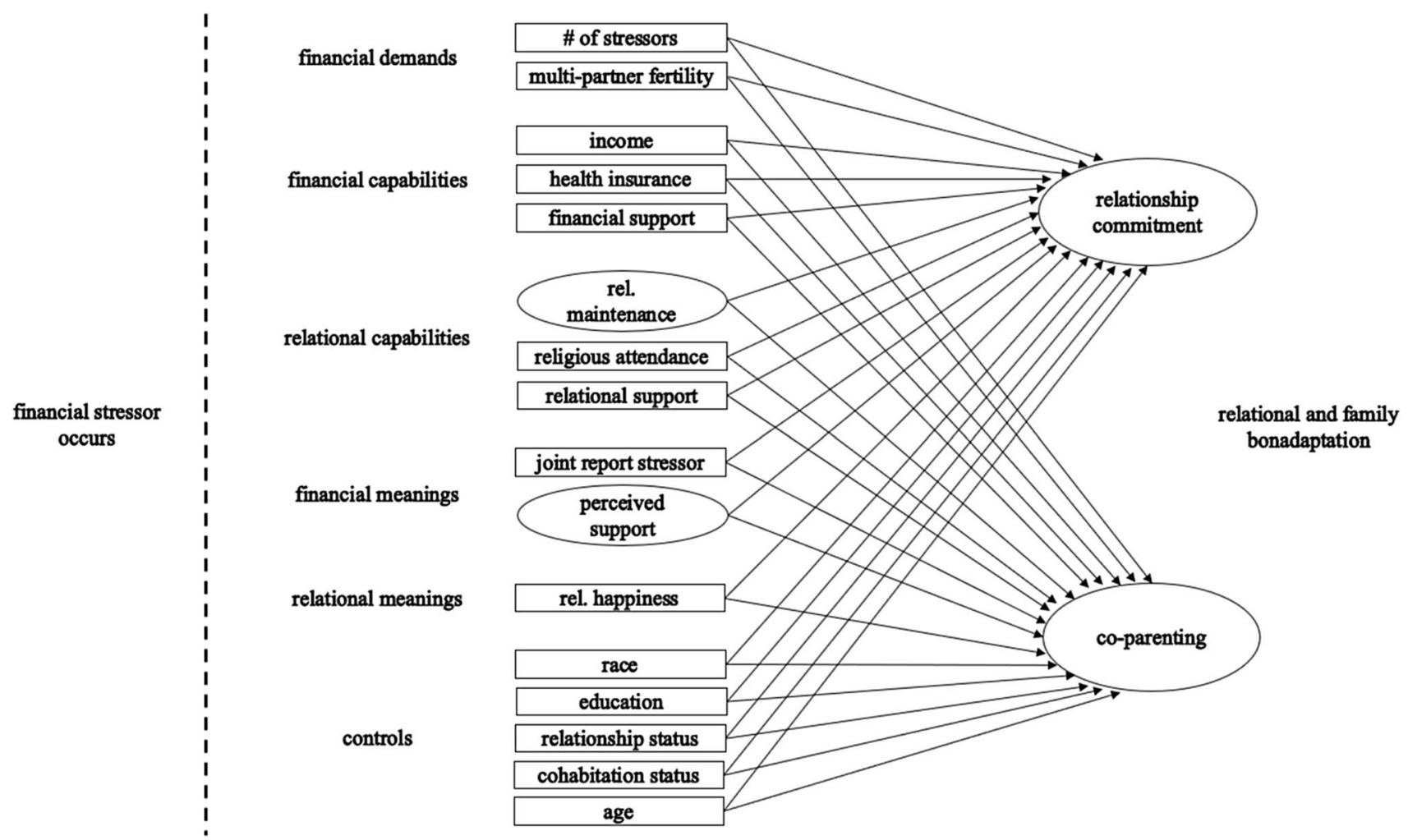

Fig. 1 Conceptual model of achieving relational bonadaptation after a financial stressor among lower-income, unmarried couples. Note Squares represent manifest constructs, and ellipses represent latent constructs

several changes have taken place; among these include the weakening of marriage, the greater acceptance of cohabitation, and the greater prevalence of nonmarital childbearing (Furstenberg 2014). Further, social class differences have widened, including that nonmarital childbearing is more often concentrated among those with lower incomes and levels of education (Furstenberg 2014; Lundberg et al. 2016). Here, bonadaptation following a financial stressor may be less likely to be conceptualized through the formation of unions such as marriage, but may be conceptualized in terms of how committed relational partners are to one another (i.e., relationship commitment) as well as how well parents work together to care for their child (i.e., coparenting).

Thus, understanding bonadaptation following a financial stressor for couples who are primarily lower-income and unmarried allows us to know if and how the FAAR model extends beyond samples of mostly married and middle- to higher-income couples, underscoring a major contribution of the current study. It is possible that the predictors of bonadaptation for Dew et al. (2018) sample are not generalizable to other types of couples, such as lower-income, unmarried couples. The current sample is distinct from the Dew et al. sample in four ways: socioeconomic status (SES), race, relationship status, and parenting status. The majority of couples in the current study are (1) lower SES (lower income and lower education), (2) people of color, (3) unmarried at baseline, and (4) experiencing the transition to parenthood. Contrasting findings between the current study and Dew et al. (2018) study would not necessarily indicate that one study is correct and the other study is incorrect; rather, contrasting findings would likely indicate that avenues of bonadaptation following a financial stressor differ according to context (e.g., sociodemographic characteristics; Greenfield 2017).

\section{Bonadaptation Among Lower-Income, Unmarried Couples}

Our conceptual model can be seen in Fig. 1. Following a financial stressor, financial and relational demands, capabilities, and meanings should all be associated with 
relational and family bonadaptation. The variables used in the current study were chosen to match as closely as possible the measures used by Dew et al. (2018). However, a few variables used by Dew et al. were either not available in the BSF dataset (i.e., economic pressure, religious marital sanctification, joint in-home religious activities) or were not relevant to our lower-income, unmarried sample (i.e., marital duration). A few additional variables were added to the current study that were not used by Dew et al. (i.e., number of financial stressors, multi-partner fertility, health insurance, perceived support network, relationship happiness, age, relationship status, and cohabitation status).

\section{Financial Stressors as a Catalyst for Relational Bonadaptation}

We focused on couples who had reported one or more financial difficulty in the past 12 months (e.g., not being able to pay the full amount of rent or mortgage that was required) because a financial stressor would fall under the demands portion of the FAAR model (Patterson 1988) and would serve as a catalyst for bonadaptation. In other words, if the stressor had not occurred, bonadaptation would not have occurred, as the process of bonadaptation requires a stressor to disrupt equilibrium (Patterson 1988).

As in the Dew et al. (2018) study, we focused on relational commitment, following the logic of Stanley and Markman (1992) who specified dedication commitment as reflecting "a desire [to] not only continue in the relationship, but also to improve it... to seek the partner's welfare, not simply one's own" (p. 595). In the Dew et al. (2018) study, improvement in dedication commitment because of the 2007-2009 Recession qualified as bonadaptation, with this type of commitment associated with beneficial relationship outcomes like greater relationship satisfaction (Stanley et al. 2002). Here, the connection to dedication commitment would be similar: higher reports of commitment would qualify as bonadaptation. Although much research on commitment is specific to married samples, other research demonstrates that higher reports of commitment are typically associated with more beneficial relational outcomes (Le and Agnew 2003). In order to have the opportunity for increased commitment and to even classify as relational bonadaptation, couples must stay together (Patterson 1988). Thus, we only included couples in the final sample who remained together over the course of the study.
Differing from the Dew et al. (2018) study, we also chose to focus on coparenting as a measure of relational bonadaptation for several reasons. First, the couples from BSF are transitioning to parenthood and negotiating new roles: partners and parents. Thus, conceptualizing bonadaptation in the face of economic adversity for these couples should also include coparenting. Second, the coparenting relationship is distinct from the romantic partner relationship (Cox and Paley 2003; Feinberg 2003), suggesting that relational commitment and coparenting should be associated with one another, but should not be the same construct. Third, some of the same stressors that contribute to marital discord, including financial stressors, can also undermine coparenting relationships (Jamison et al. 2017). Thus, the coparenting alliance represents a relevant measure of relational bonadaptation for the BSF couples.

\section{Financial Demands}

Beyond the initial stressor that all couples in our sample experienced, we included two additional constructs: number of stressors (up to three) and multi-partner fertility (MPF; having a child with someone other than the BSF partner). These variables were not used by Dew et al. (2018) but may be important demands to consider for the current sample (i.e., primarily lower-income, unmarried couples). We conceptualized MPF as a demand for the couples and the family given that critical physical, mental, and cognitive resources that are needed to maintain stable family relationships are often stretched thin for families who experience MPF (Harknett 2008). For example, parents may need to negotiate parenting, child care, and financial responsibilities with multiple individuals across different social networks (Jamison et al. 2017). Further, unmarried individuals who have children outside of marriage are more likely to experience MPF and more numerous relationship transitions than those who are married (Guzzo 2014). These findings suggest that MPF should be a demand for the couples and families in the current study.

\section{Financial and Relational Capabilities}

Capabilities can counterbalance demands and help individuals and couples achieve bonadaptation. Most of the capabilities we tested were similar to those used by Dew et al. (2018) and were associated with positive relationship outcomes. These included financial capabilities of income 
and receiving financial support (Dew 2007), as well as the relational capabilities of receiving support from one's social network for the relationship (Bryant and Conger 1999), relationship maintenance behaviors (Wilcox and Dew 2016), and religious service attendance (Fincham et al. 2008). We included religious service attendance because individuals who are integrated in a faith community might have access to financial support through that particular community (Marks et al. 2010). We also included another capability that Dew et al. (2018) did not use: health insurance. It may be that children's health insurance helps low-income couples to be more committed and to form a strong coparenting alliance because it reduces stress and promotes more positive family functioning (Brown and Kawamura 2010).

\section{Financial and Relational Meanings}

Within the FAAR model, the ways in which individuals subjectively perceive their demands and capabilities are key to how they can transform a stressful situation into bonadaption (Patterson 1988). We included two measures of financial meanings and one measure of relational meanings. First, like Dew et al. (2018), we examined whether both partners reporting financial stressors was associated with the outcome variables. Qualitative studies have found that partners working together to address financial stressors strengthens their relationship (Dew et al. 2017; Skogrand et al. 2011). Second, we examined the number of people in one's perceived support network. Although this measure was not included in Dew et al.'s (2018) study, perceived social support is a key predictor of wellbeing after a stressful situation (Cohen and Wills 1985). Similar to benefits that come from perceiving partner support during a financial stressor, perceiving a support network of others outside the partnership from which to draw upon when needed may also aid in achieving bonadaptation.

Finally, we used relationship happiness as a subjective relational meaning. When partners are relationally satisfied, they report higher commitment (Stanley et al. 2002). Further, couples who report more satisfying relationships report higher levels of coparenting cooperation and lower levels of coparenting conflict (Pedro et al. 2012). We note that Dew et al. (2018) did not test any relational meanings as predictors of bonadaptation.

Taken together, we examined the following research questions:

RQ1 Which demands, capabilities, and meanings are associated with relationship commitment following a financial stressor?

RQ2 Which demands, capabilities, and meanings are associated with coparenting following a financial stressor?

\section{Method}

\section{Participants and Procedures}

The sample for the current study was selected from the Building Strong Families Study (BSF), a multisite impact and implementation evaluation of healthy marriage and relationship education and support services for unwed parents designed to strengthen the parents' relationships while also improving child outcomes and family outcomes, such as coparenting (Wood et al. 2012). The data for the study was collected from 5102 couples who met the following inclusion criteria: at least 18 years old, in a romantic relationship, not married when the child was conceived, expected or shared a biological child who was under three months of age, and no history of intimate partner violence. Data were collected at three time points-baseline (W0): child under three months; Time 1 (W1): child is 15 months; Time 2 (W2): child is 36 months - to assess impacts of the BSF-related services, for which no significant effects were found (Wood et al. 2012).

We used two filters for the current study. First, we only included couples for which at least one partner reported a minimum of one financial stressor at $\mathrm{W} 1$; to achieve bonadaptation, participants had to have first undergone a stressor (Patterson 1988). Second, we only included couples in which both partners reported still being together at W2; an assumption of bonadaptation is that participants are still in the relationship (Patterson 1988). Accordingly, 1663 couples (i.e., $32.0 \%$ of 5102 couples; hereafter referred to as Subgroup (1) were excluded because the two partners were still together yet neither partner experienced financial stressors; 1339 couples (i.e., $26.2 \%$ of 5102 couples; hereafter referred to as Subgroup (2) were excluded because partners broke up and neither partner experienced financial stressors; 734 couples (i.e., $14.4 \%$ of 5102 couples; hereafter referred to as Subgroup (3) were excluded because at least one partner experienced financial stressors but the two partners broke up. The final sample size was 1396 heterosexual couples.

We then conducted three sets of multivariate analyses of variance to respectively examine whether Subgroup 1, Subgroup 2, and Subgroup 3 differed from the final sample on key study variables and control variables (see Table 1 for list). Based on Bandalos's (2002) criterion (partial $\eta^{2}<0.14$ ), Subgroup 2 and Subgroup 3 did not differ from the final sample in either the key study constructs or covariates, and four notable differences from 40 comparisons emerged between Subgroup 1 and the final sample. Specifically, in comparison to their counterparts in Subgroup 1, both women $\left(M_{\text {final sample }}=1.05\right.$ versus $M_{\text {Subgroup 1 }}=0.00 ; F_{(1,1394)}=905.64$, adjusted $p<0.001$, 
Table 1 Descriptive statistics for the sample

\begin{tabular}{|c|c|c|c|c|c|c|c|c|}
\hline \multirow[t]{3}{*}{ Variables } & \multicolumn{4}{|c|}{ Women } & \multicolumn{4}{|l|}{ Men } \\
\hline & \multirow[t]{2}{*}{ M } & \multirow[t]{2}{*}{ SD } & \multicolumn{2}{|l|}{ Range } & \multirow[t]{2}{*}{ M } & \multirow[t]{2}{*}{ SD } & \multicolumn{2}{|l|}{ Range } \\
\hline & & & Min & Max & & & Min & $\operatorname{Max}$ \\
\hline \multicolumn{9}{|l|}{ Bonadaptation } \\
\hline Relationship commitment & 3.18 & .57 & 1.00 & 4.00 & 3.40 & .52 & 1.33 & 4.00 \\
\hline Coparenting & 4.06 & 1.03 & 1.00 & 5.00 & 4.39 & .73 & 1.00 & 5.00 \\
\hline \multicolumn{9}{|l|}{ Financial demands } \\
\hline Number of stressors & 1.03 & .83 & .00 & 3.00 & .95 & .83 & .00 & 3.00 \\
\hline Multi-partner fertility $^{\mathrm{a}}$ & .35 & - & .00 & 1.00 & .32 & - & .00 & 1.00 \\
\hline \multicolumn{9}{|l|}{ Financial capabilities } \\
\hline Income & 1.74 & 1.57 & .00 & 7.00 & 3.05 & 1.88 & .00 & 7.00 \\
\hline Health insurance ${ }^{a}$ & .17 & - & .00 & 1.00 & .32 & - & .00 & 1.00 \\
\hline Financial support & .19 & - & .00 & 1.00 & .20 & - & .00 & 1.00 \\
\hline \multicolumn{9}{|l|}{ Relational capabilities } \\
\hline Relationship maintenance & 3.05 & .83 & 1.00 & 4.00 & 3.23 & .74 & 1.00 & 4.00 \\
\hline Religious service attendance & 2.58 & 1.10 & 1.00 & 4.00 & 2.44 & 1.06 & 1.00 & 4.00 \\
\hline Relational support & 3.20 & .79 & 1.00 & 4.00 & 3.31 & .73 & 1.00 & 4.00 \\
\hline \multicolumn{9}{|l|}{ Financial meanings } \\
\hline Stressor reported by one partner only ${ }^{a}$ & .28 & - & .00 & 1.00 & .33 & - & .00 & 1.00 \\
\hline Perceived support network ${ }^{\mathrm{a}}$ & 3.51 & 2.84 & .00 & 25.00 & 4.25 & 3.47 & .00 & 25.00 \\
\hline \multicolumn{9}{|l|}{ Relational meanings } \\
\hline Relationship happiness & 8.00 & 1.91 & .00 & 10.00 & 8.26 & 1.69 & .00 & 10.00 \\
\hline \multicolumn{9}{|l|}{ Demographics } \\
\hline White $^{\mathrm{a}}$ & .19 & - & .00 & 1.00 & .15 & - & .00 & 1.00 \\
\hline Hispanic $^{\mathrm{a}}$ & .12 & - & .00 & 1.00 & .13 & - & .00 & 1.00 \\
\hline Other race $^{\mathrm{a}}$ & .16 & - & .00 & 1.00 & .13 & - & .00 & 1.00 \\
\hline Education level $^{\mathrm{a}}$ & .66 & - & .00 & 1.00 & .64 & - & .00 & 1.00 \\
\hline Relationship status $^{\mathrm{a}}$ & .24 & - & .00 & 1.00 & .25 & - & .00 & 1.00 \\
\hline Cohabitation status ${ }^{\mathrm{a}}$ & .51 & - & .00 & 1.00 & .54 & - & .00 & 1.00 \\
\hline Age & 23.40 & 4.82 & 17.00 & 44.00 & 25.62 & 6.10 & 18.00 & 62.00 \\
\hline
\end{tabular}

${ }^{\mathrm{a}}$ For binary variables, means represent the proportion of participants who were in the category represented by 1 partial $\left.\eta^{2}=0.44\right)$ and men $\left(M_{\text {included }}=0.94\right.$ versus $M_{\text {not included }}=0.00 ; F_{(1,1394)}=780.23$, adjusted $p<0.001$, partial $\eta^{2}=0.40$ ) in the final sample reported a higher number of stressors. Also, both women $\left(M_{\text {included }}=0.28\right.$ versus $M_{\text {not included }}=0.00 ; F_{(1,1394)}=224.89$, adjusted $p<0.001$, partial $\left.\eta^{2}=0.16\right)$ and men $\left(M_{\text {included }}=0.33\right.$ versus $M_{\text {not included }}=0.00 ; F_{(1,1394)}=282.16$, adjusted $p<0.001$, partial $\eta^{2}=0.19$ ) in the final sample were more likely to have reported a financial stressor when their partner did not. Thus, the four differences between the final sample and the initial sample were all specific to financial demands. This is expected given that one of the filters was that at least one partner reported a minimum of one financial stressor (i.e., couples who did not report any financial stressors were not included in the final sample).
For the 1396 couples included in the study, the majority of the sample was Black (52\% women; 55\% men), followed by White ( $18 \%$ women; $14 \%$ men), Hispanic ( $11 \%$ women; $13 \%$ men), and other (16\% women, $13 \%$ men). About twothirds of the sample had graduated high school (or equivalent; $62 \%$ women; $60 \%$ men). About one-fourth of the sample was married by W2 (24\% women, 25\% men). (Less than $10 \%$ of couples were married at W0, which fits the sample criteria for primarily unmarried couples.) The average age was 23.40 years old $(S D=4.82)$ for women and 25.62 years old $(S D=6.10)$ for men. The average annual income was 1.74 (income category $2=\$ 5,000-9,999 ; S D=1.57$ ) for women and 3.05 (income category $3=\$ 10,000-14,999$; $S D=1.88$ ) for men. The couples in the sample were deemed primarily lower-income, given that mean annual income 
among individuals with a high school degree (or equivalent) in the US in 2005 was $\$ 26,106$ (United States Census Bureau 2017).

\section{Measures}

All items were chosen to match the measures used by Dew et al. (2018) as closely as possible. Both women's and men's reports were used for all measures with the exception of relationship status (men's and women's reports were highly correlated, $r=0.96$ ), for which only women's reports were used. Theoretically, it would be ideal for the financial stressor to precede the other variables (Patterson 1988). Thus, when data were available, demands were measured at $\mathrm{W} 1$ and all other study constructs (i.e., capabilities, meanings, relationship commitment, coparenting, and control variables) were measured at W2. We controlled for race, relationship status, cohabitation status, and age. For race (W0), there were three dummy coded variables each for men and women; these were $0=$ all else, $1=$ White (variable 1), Hispanic (variable 2), other (variable 3). Education level (W0) was coded as $0=$ less than high school, $1=$ high school diploma, GED, or high school equivalency. Relationship status (W2) was coded as $0=$ not married but still together with BSF partner, $1=$ married to BSF partner). Cohabitation status (W2) was coded as $0=$ not living with BSF partner all of the time, $1=$ living with BSF partner all of the time. Finally, age (W0) was a continuous variable.

\section{Financial Demands}

We used two measures of financial demands. The first was the number of financial stressors-a count variable (from 0 to 3 ) summing participants' responses $(0=$ no, $1=$ yes $)$ to the following three items at W1: "In the past year, I have experienced (1) inability to pay the full amount of rent or the mortgage, (2) having utilities shut off, (3) eviction." Higher scores indicated more demands. The second measure was whether or not participants had multi-partner fertility (MPF) at W0; whether or not participants had children with someone other than their BSF partner. The variable was originally a count variable in that participants were asked "How many children do you have with other partners?" The variable was recoded to indicate either presence or absence of MPF $(0=$ no MPF, $1=$ MPF $)$.

\section{Financial Capabilities}

We used three measures of financial capabilities. The first, income, was measured using the following item from W0: "In the last 12 months, what have been your total earnings from all jobs before tax and deduction?"
Response categories were as follows: $0=\$ 0,1=\$ 1-4,999$, $2=\$ 5,000-9,999,3=\$ 10,000-14,999,4=\$ 15,000-19,999$, $5=\$ 20,000-24,999,6=\$ 25,000-34,999,7=\$ 35,000$ plus. For the second, health insurance (W2), participants responded to the following item: "Is your child currently covered by health insurance through your or someone else's employer?" $0=$ no, $1=$ yes. For the third, financial support received (W2), participants responded to the following item: "Did you, your partner, or the children who live with you receive money from friends or relatives in the past month?" $0=$ no, $1=$ yes.

\section{Relational Capabilities}

We used three measures of relational capabilities. Three items (women: $\leq 0.83$; men: $\leq 0.84$ ) were used to measure relationship maintenance behaviors (W2): "Partner can be counted on to help me," "Partner respects me," and "Partner shows love and affection for me." The items were measured on a four-point Likert scale ( $1=$ often to $4=$ never), and all items were reverse coded such that higher scores indicated more maintenance behaviors. As a second measure of relational capabilities, we used the report of religious service attendance (W2): "In the past 12 months, about how often have you attended a religious service?" This was measured on a four-point Likert scale ( $1=$ never to $4=$ once a week or more), such that higher scores indicated more frequent attendance. Finally, we used the following item to measure relational support (W2): "My friends and relatives support my relationship with my partner." This item was measured on a four-point Likert scale $(1=$ strongly agree to $4=$ strongly disagree), and the item was reverse coded such that higher scores indicated more relational support.

\section{Financial Meanings}

We used two measures of financial meanings. The first was whether or not partners both reported having experienced at least one financial stressor (compared to only the woman reporting a financial stressor or only the man reporting a financial stressor). That is, this item measured whether or not participants went through a stressor together with their partner (even if they reported differing stressors). To create this item, we constructed two new variables from the following three items previously mentioned (W1): "In the past year, I have experienced (1) inability to pay the full amount of rent or the mortgage, (2) having utilities shut off, (3) eviction." In the first new item, $0=$ all else (either woman only reported or both reported), $1=$ man only reported stressor(s), and in the second new item, $0=$ all else (either man only reported or both reported), $1=$ woman only reported stressor(s). As a second measure of financial meanings, we used three 
items (women: $\leq 0.80 ;$ men: $\leq 0.77$ ) that together measured perceived support network (W2): "The number of people (besides your partner) who could (1) provide emergency child care, (2) loan the respondent $\$ 100$, (3) provide help or advice." This was a count variable, as participants could respond with a number up to 25 people for each item.

\section{Relational Meanings}

We used one measure of relational meanings: relationship happiness (W2). Participants responded to the following item: "On a scale from 0 to 10 , where 0 is not at all happy and 10 is completely happy, how happy would you say your relationship with your partner is?" Thus, higher scores indicated greater relationship happiness.

\section{Relational Bonadaptation}

We used relationship commitment (W2; women: $\leq 0.59$; men: $\leq 0.66)$ as one measure of relational bonadaptation. Participants responded to three dedication commitment items from Stanley and Markman's (1992) Commitment Inventory: "I may not want to be with my partner a few years from now", "My relationship with my partner is more important than almost anything else in life" (reverse coded), and "I want this relationship to stay strong no matter what rough times we may have" (reverse coded). The items were measured on a four-point Likert scale (ranging from $1=$ often to $4=$ never). After reverse coding two items, higher scores indicated greater commitment.

We used quality of coparenting (W2; women: $\leq 0.97$; men: $\leq 0.94)$ as the second measure of relational bonadaptation. Participants responded to 10 items on the Parenting Alliance Inventory (Abidin and Brunner 1995). Using a five-point Likert scale (ranging from $1=$ strongly agree to $5=$ strongly disagree), participants were asked to state their level of agreement with 10 statements. Sample statements include "My partner and I communicate well about our child" and "My partner makes my job of being a parent easier." All items were reverse coded so that higher scores indicated higher coparenting.

\section{Data Analysis Plan}

Analyses were conducted using Mplus Version 7. For all models, missing data were handled using the full information maximum likelihood (FIML) method (Enders 2010). We conducted a structural equation model (SEM) to (1) include latent variables to partial out measurement errors and (2) simultaneously examine directional linear associations (i.e., predictive pathways from predictors to outcomes; e.g., the pathways from financial demands to commitment or coparenting) and nondirectional linear associations (i.e., correlations among variables; e.g., correlations between fathers' and mothers' commitment given interdependence between two partners within a couple) among all variables of interest (MacCallum and Austin 2000).

To evaluate model fit, the following indices were used: Chi-square value, comparative fit index (CFI), root mean square error of approximation (RMSEA), and standardized root mean-square residual (SRMR) (Kline 2015). The following were used as requirements for "adequate" model fit: CFI $>0.90$, RMSEA $<0.08$, and SRMR $<0.08$; and the following were used for "good" model fit: CFI $>0.95$, RMSEA $<0.05$, SRMR $<0.05$ (Little 2013). Analyses were conducted in two stages: measurement invariance tests and pathway analyses.

\section{Measurement Invariance Tests}

A measurement model was first estimated to examine factor loadings of latent constructs as well as model fit. All study variables were included in the model (separate variables for women and men), with relationship maintenance behaviors, perceived support network, relationship commitment, and coparenting as latent constructs.

We conducted measurement invariance tests to examine whether the scales were measuring the same constructs among men and women as well as whether the scores of men and women were comparable. Given the interdependence between two partners within a couple, we followed guidelines by Little (2013) and conducted longitudinal configural factorial analyses on relationship maintenance behaviors, perceived support network, commitment, and coparenting in separate models. As Little (2013) and Kline (2015) suggested, three levels of invariance were tested. Configural invariance is the least restrictive level of measurement invariance. It is tested by specifying the same CFA model for each partner. In this model, both the number of factors and the covariance among factors and among indicators are the same, but all parameters are freely estimated. Weak invariance is the second level of measurement invariance and assumes configural invariance. This hypothesis is tested by (1) imposing an equality constraint across gender on the unstandardized loading of each indicator, and (2) comparing the model fit of the weak invariance model with that of the configural invariance model. Strong invariance is the third level of measurement invariance and assumes weak invariance. It requires equal unstandardized intercepts of indicators 
Table 2 Standardized factor loadings for latent constructs

\begin{tabular}{lll}
\hline Indicators & Women & Men \\
\hline Relationship maintenance behaviors & & \\
Partner can be counted on to help me & .87 & .82 \\
Partner respects me & .82 & .81 \\
Partner shows love and affection for me & .84 & .86 \\
Perceived support network & & \\
Provide emergency child care & .73 & .77 \\
Loan me \$100 & .73 & .72 \\
Provide help or advice & .80 & .69 \\
Relationship commitment & & \\
I may not want to be with my partner a few years from now & .72 & .66 \\
My relationship with my partner is more important than almost anything else in life & .62 & .72 \\
I want this relationship to stay strong no matter what rough times we may have & .88 & .87 \\
Coparenting & & \\
Good parent & .85 & .77 \\
Communicate well & .85 & .78 \\
Good judgment & .86 & .84 \\
Job easier & .86 \\
Good team & .87 & .84 \\
Handle children & .85 \\
Polve problems & .80 & .85 \\
Like talking & .83 & .83 \\
Pays attention & .87 & .79 \\
\hline
\end{tabular}

across gender. This hypothesis is tested by (1) imposing an equality constraint across time and gender on the intercepts of each indicator, and (2) comparing the model fit of the strong invariance model with that of weak invariance model. For the test of weak and strong invariance, if the fit of a more restrictive model is not significantly worse than that of the less restrictive model, the more restrictive hypothesis is retained. For the criteria of significantly worse model fit, researchers have suggested that an increase in CFA by 0.01 or more indicates deviation from measurement invariance (for review, see Kline 2015). To be comparable, the measurement of key constructs for men and women should at least meet the criteria of weak invariance.

\section{Pathway Analyses}

An actor-partner interdependence structural equation model (APIM; Kenny et al. 2006) was estimated to test associations from demands, capabilities, and meanings to relationship commitment and coparenting. Regression paths were estimated from number of stressors, MPF, income, health insurance, financial support, relationship maintenance behaviors, religious service attendance, relational support, joint reporting of stressor, perceived support network, and relationship happiness onto relationship commitment and coparenting. We controlled for race, education level, relationship status, cohabitation status, and age. All exogenous variables (and controls) were correlated with each other. Corresponding female/male items of all latent constructs were correlated with each other, as were corresponding female/male endogenous variables, to account for couple nonindependence.

\section{Results}

\section{Preliminary Analyses}

Descriptive statistics were estimated across gender (Table 1). Overall, women and men in the current study experienced low levels of financial demands as well as high levels of bonadaptation, financial capabilities, relational capabilities, financial meanings, and relational meanings. Correlations among key study variables and covariates are available in the Appendix Document. 
Table 3 Standardized coefficients for pathways to commitment

\begin{tabular}{|c|c|c|}
\hline & \multicolumn{2}{|c|}{ Commitment } \\
\hline & Women & Men \\
\hline \multicolumn{3}{|l|}{ Financial demands } \\
\hline W number of stressors & .01 & .02 \\
\hline M number of stressors & -.03 & -.00 \\
\hline $\mathrm{W} \operatorname{MPF}(0=$ no $)$ & -.01 & $-.08 * * *$ \\
\hline $\mathrm{M} \operatorname{MPF}(0=$ no $)$ & -.03 & .02 \\
\hline \multicolumn{3}{|l|}{ Financial capabilities } \\
\hline W Income & -.00 & .02 \\
\hline M Income & -.01 & .01 \\
\hline W Health Insurance $(0=$ no $)$ & $.05^{*}$ & -.04 \\
\hline$M$ health insurance $(0=$ no $)$ & -.03 & .00 \\
\hline W financial support $(0=$ no $)$ & .02 & -.02 \\
\hline M financial support $(0=$ no $)$ & .01 & .04 \\
\hline \multicolumn{3}{|l|}{ Relational capabilities } \\
\hline $\mathrm{W}$ relationship maintenance & $.85 * * *$ & .03 \\
\hline $\mathrm{M}$ relationship maintenance & .03 & $.94 * * *$ \\
\hline $\mathrm{W}$ religious service attendance & .02 & -.04 \\
\hline $\mathrm{M}$ religious service attendance & .01 & .04 \\
\hline $\mathrm{W}$ relational support & .02 & -.01 \\
\hline M relational support & .03 & .01 \\
\hline \multicolumn{3}{|l|}{ Financial meaning } \\
\hline W only reported stressor & -.06 & -.03 \\
\hline M only reported stressor & .00 & .02 \\
\hline W perceived support network & -.01 & -.01 \\
\hline M perceived support network & -.01 & -.01 \\
\hline \multicolumn{3}{|l|}{ Relational meaning } \\
\hline $\mathrm{W}$ relationship happiness & .05 & -.03 \\
\hline M relationship happiness & -.03 & -.03 \\
\hline \multicolumn{3}{|l|}{ Controls } \\
\hline $\mathrm{W}$ white $(0=$ else $)$ & -.01 & .01 \\
\hline M white $(0=$ else $)$ & .04 & .01 \\
\hline $\mathrm{W}$ hispanic $(0=$ else $)$ & -.02 & -.02 \\
\hline M hispanic $(0=$ else $)$ & .00 & .02 \\
\hline $\mathrm{W}$ other race $(0=$ else $)$ & .01 & -.00 \\
\hline M other race $(0=$ else $)$ & .01 & .02 \\
\hline W education $(0=$ less than HS $)$ & .01 & .01 \\
\hline M education $(0=$ less than $\mathrm{HS})$ & -.01 & -.01 \\
\hline Married $(0=$ not married $)$ & $.08 * * *$ & $.08 * * *$ \\
\hline W cohabiting $(0=$ not cohabit $)$ & .05 & .02 \\
\hline$M$ cohabiting $(0=$ not cohabit $)$ & .02 & .00 \\
\hline W age & -.00 & .01 \\
\hline M age & -.01 & -.03 \\
\hline
\end{tabular}

The left-hand column represents all exogenous variables (and controls); the top row of variable names represents endogenous variables. $\mathrm{W}=$ Women; $\mathrm{M}=$ Men

${ }^{*} p<.05 .{ }^{* *} p<.01 .{ }^{* * *} p<.001$
Table 4 Standardized coefficients for pathways to coparenting

\begin{tabular}{|c|c|c|}
\hline & \multicolumn{2}{|c|}{ Coparenting } \\
\hline & Women & Men \\
\hline \multicolumn{3}{|l|}{ Financial demands } \\
\hline W Number of stressors & .04 & .05 \\
\hline M Number of stressors & -.01 & $-.08 * *$ \\
\hline $\mathrm{W} \operatorname{MPF}(0=$ no $)$ & -.02 & -.03 \\
\hline $\operatorname{M~MPF~}(0=$ no $)$ & .01 & -.02 \\
\hline \multicolumn{3}{|l|}{ Financial capabilities } \\
\hline W Income & .03 & .03 \\
\hline M Income & .03 & -.03 \\
\hline W Health insurance $(0=$ no $)$ & $.05^{* *}$ & -.02 \\
\hline M Health insurance $(0=$ no $)$ & -.02 & .03 \\
\hline W Financial support $(0=$ no $)$ & $.05 * *$ & $-.05^{*}$ \\
\hline M Financial support $(0=$ no $)$ & -.00 & $.05 * *$ \\
\hline \multicolumn{3}{|l|}{ Relational capabilities } \\
\hline W Relationship maintenance & $.76 * * *$ & .10 \\
\hline M Relationship maintenance & $.08^{*}$ & $.79 * * *$ \\
\hline W Religious service attendance & -.00 & .02 \\
\hline M Religious service attendance & .01 & .01 \\
\hline W Relational support & -.01 & -.08 \\
\hline M Relational support & -.00 & .04 \\
\hline \multicolumn{3}{|l|}{ Financial meaning } \\
\hline W Only reported stressor & .00 & -.06 \\
\hline M Only reported stressor & .04 & .01 \\
\hline W Perceived support network & -.02 & $.04 *$ \\
\hline M Perceived support network & -.01 & -.02 \\
\hline \multicolumn{3}{|l|}{ Relational meaning } \\
\hline W Relationship happiness & $.13^{* *}$ & -.02 \\
\hline M Relationship happiness & -.06 & .04 \\
\hline \multicolumn{3}{|l|}{ Controls } \\
\hline W White $(0=$ else $)$ & .02 & .01 \\
\hline M White $(0=$ else $)$ & -.02 & -.03 \\
\hline W Hispanic $(0=$ else $)$ & -.00 & .01 \\
\hline M Hispanic $(0=$ else $)$ & -.01 & -.02 \\
\hline W Other race $(0=$ else $)$ & -.01 & .02 \\
\hline M Other race $(0=$ else $)$ & .01 & -.04 \\
\hline W Education $(0=$ less than HS $)$ & -.03 & .01 \\
\hline M Education $(0=$ less than HS $)$ & .02 & -.01 \\
\hline Married $(0=$ not married $)$ & -.03 & -.03 \\
\hline W Cohabiting $(0=$ not cohabit $)$ & -.00 & .02 \\
\hline M Cohabiting $(0=$ not cohabit $)$ & $.06 *$ & -.02 \\
\hline W Age & .01 & .04 \\
\hline M Age & .01 & $-.05^{*}$ \\
\hline
\end{tabular}

The left-hand column represents all exogenous variables (and controls); the top row of variable names represents endogenous variables. $\mathrm{W}=$ Women; $\mathrm{M}=$ Men

${ }^{*} p<.05 . * * p<.01 . * * * p<.001$ 
Overall, all correlations were in expected directions; financial demands were negatively associated with bonadaptation; financial capabilities, relational capabilities, financial meanings, and relational meanings were positively associated with bonadaptation.

\section{Measurement Model}

The measurement model with all latent constructs fit adequately: $\chi^{2}(1672)=5238.34, p<0.001 ; \mathrm{CFI}=0.93$; RMSEA $=0.04$ with $90 \%$ Confidence Interval [0.038, 0.040]; SRMR $=0.13$. Standardized factor loadings are in Table 2; all factor loadings were above 0.60. Per the measurement invariance test, relationship maintenance behaviors, perceived support network, and commitment met the criteria of weak invariance; coparenting met the criteria of strong invariance. As such, the measurement for the key study constructs were equivalent across gender, and we were able to compare the levels of relationship maintenance behaviors, perceived support network, commitment, and coparenting between men and women.

\section{Pathway Analyses}

The APIM had good model fit: $\chi^{2}(1548)=3431.69$, $p<0.001 ; \mathrm{CFI}=0.95$; $\mathrm{RMSEA}=0.03$ with $90 \%$ Confidence Interval [0.028, 0.031]; SRMR $=0.02$. The model explained $97 \%$ of the variance in relationship commitment for women and $94 \%$ for men, and $81 \%$ of the variance in coparenting alliance for women and $73 \%$ for men. Standardized coefficients for pathways to commitment are displayed in Table 3, and standardized coefficients for pathways to coparenting alliance are displayed in Table 4. Several significant findings emerged.

\section{Which demands, capabilities, and meanings are associated with relationship commitment (RQ1) and with coparenting (RQ2) following a financial stressor?}

For financial demands, women's MFP was negatively associated with men's commitment $(\beta=-0.08, p<0.001)$; and men's number of stressors was negatively associated with men's coparenting $(\beta=-0.08, p<0.01)$.

For financial capabilities, women's health insurance was positively associated with women's relationship commitment $(\beta=0.05, p<0.05)$ and coparenting $(\beta=0.05, p<0.01)$. Women's financial support was positively associated with women's coparenting $(\beta=0.05, p<0.01)$ but negatively associated with men's coparenting $(\beta=-0.05, p<0.05)$. Men's financial support was positively associated with men's coparenting $(\beta=0.05, p<0.01)$.

For relational capabilities, women's relationship maintenance behaviors were positively associated with women's commitment $(\beta=0.85, p<0.001)$ and coparenting $(\beta=0.76$, $p<0.001)$; men's relationship maintenance were positively associated with men's commitment $(\beta=0.94, p<0.001)$ and coparenting $(\beta=0.79, p<0.001)$ as well as women's coparenting $(\beta=0.08, p<0.05)$.

For financial meanings, women's perceived support network was positively associated with men's coparenting $(\beta=0.04, p<0.05)$.

For relational meanings, women's relationship happiness was positively associated with women's coparenting $(\beta=0.13, p<0.01)$.

\section{Discussion}

Two findings are of particular note. First, the results show that predictors of coparenting are more numerous than predictors of commitment. Second, relationship maintenance behaviors and financial support are capabilities for both the current study sample (i.e., primarily lower-income, unmarried couples) as well as Dew et al.,'s (2018) sample (i.e., nationally-representative married couples), whereas other capabilities and meanings are sample-specific.

\section{Bonadaptation Among Lower-Income, Unmarried Couples}

First, we will discuss the results regarding Research Questions 1 and 2. It is of note that at least one predictor under each facet of the FAAR model (i.e., financial demands, financial capabilities, relational capabilities, financial meanings, and relational meanings) was significantly associated with relational bonadaptation; this suggests that each facet of the FAAR model matters.

\section{Financial Demands}

Two significant, negative associations emerged between financial demands and bonadaptation (i.e., women's MPF with men's commitment; men's number of stressors and men's coparenting). This suggests that although financial stressors may serve as a catalyst for positive relational 
Table 5 Comparison of Findings Between Dew et al. (2018) and Current Study (BSF)

\begin{tabular}{|c|c|c|c|c|c|c|}
\hline & \multicolumn{4}{|c|}{ DV: commitment } & \multicolumn{2}{|l|}{ DV: coparenting } \\
\hline & \multicolumn{2}{|l|}{ Women } & \multicolumn{2}{|l|}{ Men } & \multirow{2}{*}{$\begin{array}{l}\text { Women } \\
\text { BSF }\end{array}$} & \multirow{2}{*}{$\begin{array}{l}\text { Men } \\
\text { BSF }\end{array}$} \\
\hline & Dew et al & BSF & Dew et al & BSF & & \\
\hline \multicolumn{7}{|l|}{ Financial demands } \\
\hline Number of stressors & - & $\mathrm{n} / \mathrm{s}$ & - & $\mathrm{n} / \mathrm{s}$ & $\mathrm{n} / \mathrm{s}$ & Actor (-) \\
\hline Multi-partner fertility & - & $\mathrm{n} / \mathrm{s}$ & - & Partner (-) & $\mathrm{n} / \mathrm{s}$ & $\mathrm{n} / \mathrm{s}$ \\
\hline \multicolumn{7}{|l|}{ Financial capabilities } \\
\hline Income & $\mathrm{n} / \mathrm{s}$ & $\mathrm{n} / \mathrm{s}$ & $\mathrm{n} / \mathrm{s}$ & $\mathrm{n} / \mathrm{s}$ & $\mathrm{n} / \mathrm{s}$ & $\mathrm{n} / \mathrm{s}$ \\
\hline Health insurance & - & Actor (+) & - & $\mathrm{n} / \mathrm{s}$ & Actor (+) & $\mathrm{n} / \mathrm{s}$ \\
\hline Financial support & Actor (+) & $\mathrm{n} / \mathrm{s}$ & Actor (+) & $\mathrm{n} / \mathrm{s}$ & Actor (+) & Actor $(+)$ partner $(-)$ \\
\hline \multicolumn{7}{|l|}{ Relational capabilities } \\
\hline Relationship maintenance & Actor (+) & $\operatorname{actor}(+)$ & Actor (+) & Actor (+) & Actor (+) partner (+) & Actor (+) \\
\hline Religious service attendance & $\mathrm{n} / \mathrm{s}$ & $\mathrm{n} / \mathrm{s}$ & $\mathrm{n} / \mathrm{s}$ & $\mathrm{n} / \mathrm{s}$ & $\mathrm{n} / \mathrm{s}$ & $\mathrm{n} / \mathrm{s}$ \\
\hline Religious marital sanctification & Actor (+) & - & Actor (+) & - & - & - \\
\hline Joint in-home religious activities & $\mathrm{n} / \mathrm{s}$ & - & $\mathrm{n} / \mathrm{s}$ & - & - & - \\
\hline Relational support & Actor (+) & $\mathrm{n} / \mathrm{s}$ & Actor (+) & $\mathrm{n} / \mathrm{s}$ & $\mathrm{n} / \mathrm{s}$ & $\mathrm{n} / \mathrm{s}$ \\
\hline \multicolumn{7}{|l|}{ Financial meanings } \\
\hline Both reported stressors or not & Significant & $\mathrm{n} / \mathrm{s}$ & $\mathrm{n} / \mathrm{s}$ & $\mathrm{n} / \mathrm{s}$ & $\mathrm{n} / \mathrm{s}$ & $\mathrm{n} / \mathrm{s}$ \\
\hline Perceived support network & - & $\mathrm{n} / \mathrm{s}$ & - & $\mathrm{n} / \mathrm{s}$ & $\mathrm{n} / \mathrm{s}$ & Partner (+) \\
\hline Recession stressed marriage & Actor (+) & - & Actor (+) & - & - & - \\
\hline \multicolumn{7}{|l|}{ Relational meanings } \\
\hline Relationship happiness & - & $\mathrm{n} / \mathrm{s}$ & - & $\mathrm{n} / \mathrm{s}$ & Actor (+) & $\mathrm{n} / \mathrm{s}$ \\
\hline
\end{tabular}

Control variables are not listed for parsimony. Significant associations are bolded. The direction of the association is indicated in parentheses, either positive (+) or negative (-). $n / s$ not significant, actor significant actor effect, partner significant partner effect. When a variable was not included in a study, it is indicated by a dash

growth (Dew et al. 2018; Kelley et al. 2018), financial demands may also be harmful to bonadaptation. For example, given our findings, it is possible that when economically disadvantaged men are faced with many financial demands, they must prioritize financial provision over coparenting alliance, financial stress undermines the ability to engage in a coparenting alliance with their partners, and/or mothers engage in more gatekeeping behaviors (Jamison et al. 2017; Waller 2012).

\section{Financial and Relational Capabilities}

There were many significant associations between capabilities and bonadaptation (i.e., women's health insurance with women's commitment and coparenting; women's financial support with women's and men's coparenting; men's financial support with men's coparenting; women's relationship maintenance behaviors with women's commitment and coparenting; men's relationship maintenance behaviors with men's commitment and coparenting and women's coparenting). All associations were positive, with one exception: women's financial support was negatively associated with men's coparenting. It is possible that when women receive financial support from family members or friends it is because their male partner is to some degree absent or uninvolved (Waller 2012). Or, it is also possible that when women receive financial support from family members or friends it hurts their male partner's self-perceived alignment with concepts such as hegemonic masculinity (e.g., a self-perception that he has failed in his breadwinner role; Curran et al. 2015; LeBaron et al. 2019) and may negatively influences his self-reported ability to coparent. Given that all other associations between capabilities and bonadaptation were positive, it seems that on the whole financial and relational capabilities are helpful in achieving relational bonadaptation.

\section{Financial and Relational Meanings}

Finally, two significant associations emerged between meanings and bonadaptation (i.e., women's perceived support network with men's coparenting; women's relationship happiness with women's coparenting). Both associations were positive. It is of note that an individual's subjective perception can influence not only their own 
outcomes but their partner's as well. Previous studies have also found strong links between financial perceptions and relationship outcomes (e.g., Britt et al. 2017; Curran et al. 2018; Dew 2009; Hill et al. 2017; Serido et al. 2015; Totenhagen et al. 2020) as well as between relational meanings and relationship outcomes such as commitment (Le and Agnew 2003). Our findings suggest that after a financial stressor, positive perceptions about one's financial situation and one's relationship can help in achieving relational bonadaptation.

\section{Comparing the Findings of Two Samples}

Table 5 shows a comparison of Dew et al. (2018) findings and the findings from the current study. Although some variables were only tested in one of the two samples, there are several notable comparisons. First, relationship maintenance behaviors and, to a lesser degree, financial support appear to be generalizable capabilities (i.e., consistently predictive across samples). Conversely, other predictors seem to be sample-specific in their association with bonadaptation. For example, Dew et al. (2018) found significant actor associations between relational support and commitment for both women and men, while the current study found no significant associations for relational support, either with commitment or coparenting. It is also of note that Dew et al. (2018) found no significant partner effects, while several were found in the current study.

Coparenting was associated with more constructs (compared to relationship commitment) for the current sample (i.e., lower-income, unmarried couples). Financial support was significantly associated with commitment in the Dew et al. sample (i.e., nationally representative married couples) but not in the current sample; however, financial support was significantly associated with coparenting in the current sample. Additionally, in the current sample there were many more significant associations between predictors and coparenting than there were between predictors and commitment. It is possible that coparenting is associated with more constructs than relationship commitment for the current sample because all couples were making the commitment to parent together at the time of the study (i.e., they were having their first child together), but not all couples were necessarily committing to each other at the time of the study (e.g., all were unmarried at W0). Thus, when measuring positive relational growth after a financial stressor, it may be important to consider the nature and development of the relationships being examined.

\section{Implications}

There are several implications of our findings for research, practice, and policy. Chiefly, as clinicians help couples achieve relational bonadaptation after a financial stressor, it is important that they consider the couple's context (e.g., SES, relationship status). While some avenues to bonadaptation seem to be generalizable (e.g., relationship maintenance behaviors), others may be context-specific (e.g., relational support). Clinicians working with lowerincome, unmarried couples can help these couples lessen the number of financial stressors they experience, make intentional choices about MPF, gain access to children's health insurance, identify and utilize financial support networks, increase relationship maintenance behaviors, and increase relationship happiness. By doing so, clinicians may be able to help their lower-income, unmarried clients strengthen their relationship commitment and coparenting even as their clients experience financial stressors. We acknowledge that many practitioners already do many of these things. Further, we also acknowledge that in spite of these efforts, many low-income families continue to struggle with attaining and maintaining financial capability. Our study is important, however, because it demonstrates the many things (e.g., perceived support network) that can help low-income couples in both financial and family domains. That is, this study adds to a burgeoning literature (e.g., Kelley et al. 2018) that suggests that financial and relationship issues are intertwined and that they may influence each other in a bi-directional way.

It is also of note that, for both the Dew et al. (2018) sample (i.e., nationally representative married couples) and the BSF sample (i.e., primarily lower-income, unmarried couples), income was not significantly associated with relational bonadaptation, while financial support was significantly predictive across both samples. This is good news for clinicians in that although it may be difficult for clients to increase their income, it may be more possible for them to (assisted by the clinician) identify and utilize financial support networks. Financial and relational meanings may serve as particularly successful intervention points, as perceptions and meaning-making may be easier to adjust than decreasing demands or increasing capabilities (Shapiro 2007). Further, given that shared financial meaning between partners has been associated with positive relationship outcomes, at least clinically (Shapiro 2007), clinicians can help their clients create shared meaning around both their financial and relational situations. 
A number of other implications exist as well. For example, this study acts as a caution for researchers, as well as those who read and apply the work of researchers, to be aware of the potential limits to the generalizability of their findings and make any generalizations carefully. That is, researchers might be more aware of the limitations of their sampling designs as they discuss their findings. While some of the Dew et al. (2018) findings generalized across samples, some did not. And although these all might be obvious statements that "go without saying," many researchers continue to make this mistake. Finally, policy makers should take into consideration the avenues for relational bonadaptation as well as the importance of couples' context when making decisions about policy. For example, it seems as though, at least for primarily lowerincome, unmarried couples, access to health insurance may help in alleviating the relational burden of financial stressors.

\section{Strengths, Limitations, and Future Research}

It should be noted that several of the coefficients were relatively small in terms of effect sizes (i.e., Betas smaller than 0.1 ; Cohen 1992). Additionally, several study variables were measured at non-ideal time points (e.g., income measured at W0 instead of W2). Finally, the current study is limited in its measures of bonadaptation (i.e., relationship commitment and coparenting scales); that is, we do not actually know whether romantic partners perceived that financial stressors caused relational bonadaptation or not, we could only include them as precursors (W1) to the relational bonadaptation reports (W2).

While both Dew et al. (2018) study and the current study tested associations of demands, capabilities, and meanings with relational bonadaptation, future research could test the interaction of demands, capabilities, and meanings. Here are two examples: (1) Perhaps some capabilities are uniquely suited to counteract certain demands. (2) Perhaps the associations of demands and capabilities with bonadaptation depend on the perceptions couples have about those demands and capabilities. Finally, future research could test other financial demands, financial and relational capabilities, and financial and relational meanings as predictors of relational bonadaptation following a financial stressor.

\section{Conclusion}

Using Patterson's (1988) FAAR model as a guide, we examined how financial and relational demands, capabilities, and meanings were associated with relational bonadaptation.
Dew et al. (2018) did so using a nationally-representative sample of married couples. We tested the generalizability of Dew et al. (2018) findings using a sample of primarily lower-income, unmarried couples, and compared the findings between the two samples. The results suggest that as researchers and clinicians help couples achieve relational bonadaptation after a financial stressor, it is important that they consider the couple's context (e.g., SES, relationship status). For example, although relationship maintenance behaviors and financial support appear to be generalizable capabilities (i.e., consistently predictive across samples), other capabilities and meanings seem to be context-specific. Additionally, it seems as though coparenting may be a salient measure of relational bonadaptation for primarily lower-income, unmarried couples. Finally, the results also suggest that although the avenues to bonadaptation may differ depending on context, it may be possible for couples to thrive not just in spite of financial stressors but even because of them; financial stressors can serve as catalysts for positive relational growth.

Funding Funding was provided by Administration for Children and Families (Grant No. 90PD0287-01).

\section{Compliance with Ethical Standards}

Conflict of interest The authors declare that they have no conflict of interest.

Ethical Approval IRB approval for the research project was secured by the company, Mathematica Policy Research, Inc.

Informed Consent All participants signed a consent form prior to participation and the person administering the form also signed their name.

\section{Appendix}

Appendix document \#1 correlations among key study variables and covariates.

Pearson correlation coefficients were estimated to gauge bivariate relationships between variables. As displayed in Appendix Table 6, all correlations were in expected directions; financial demands were negatively associated with bonadaptation; financial capabilities, relational capabilities, financial meanings, and relational meanings were positively associated with bonadaptation. 


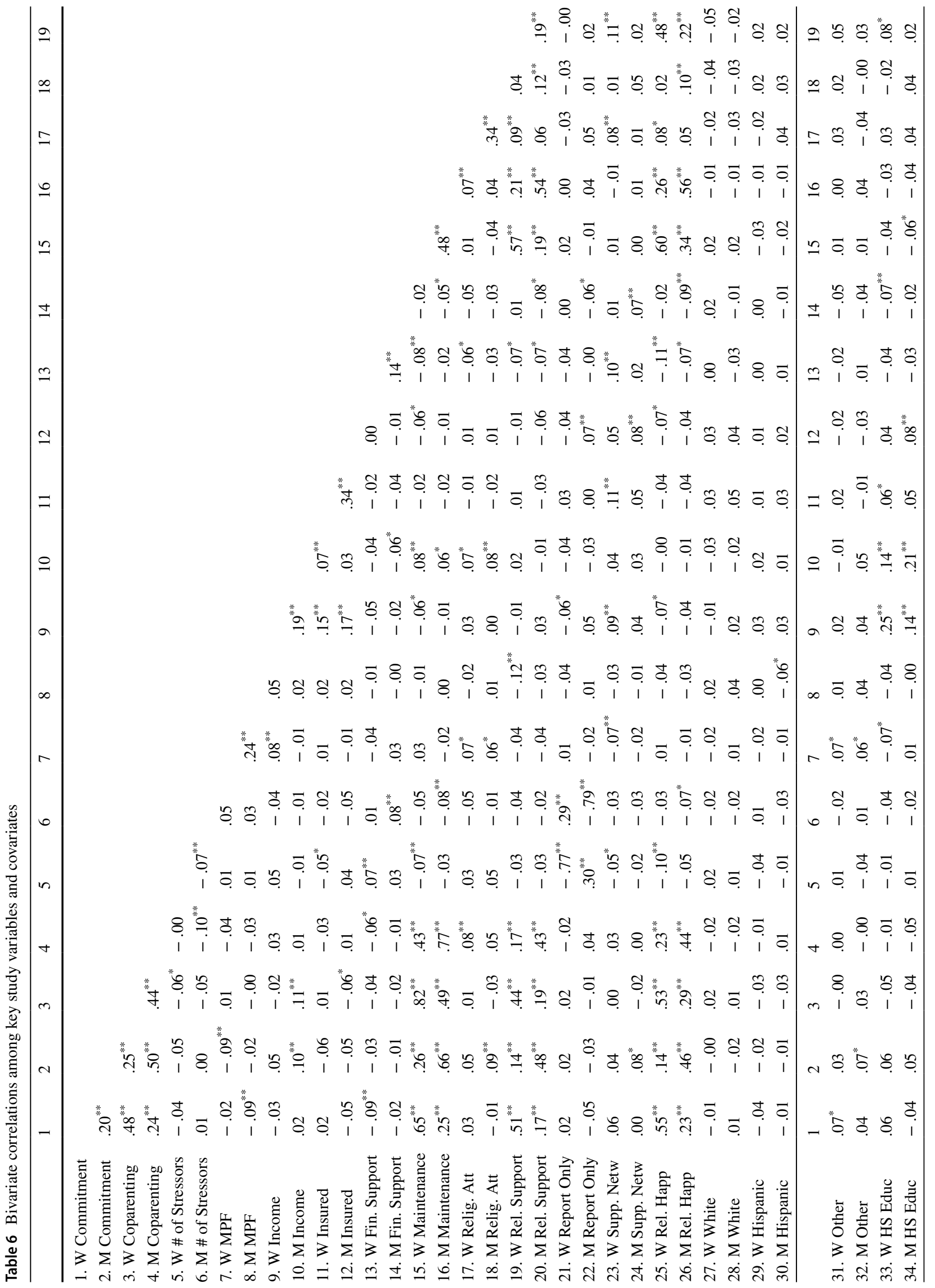




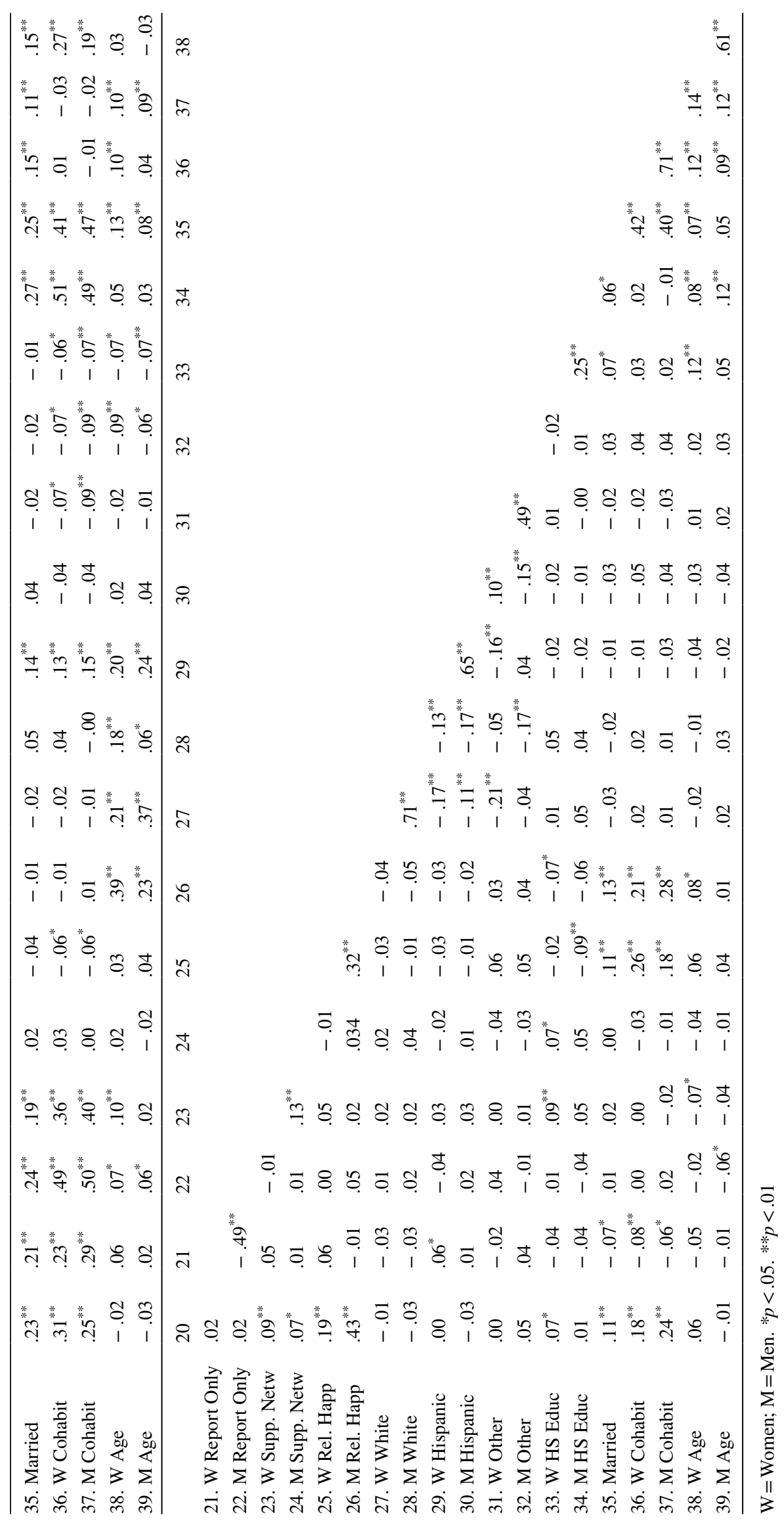




\section{References}

Abidin, R. R., \& Brunner, J. F. (1995). Development of a parenting alliance inventory. Journal of Clinical Child Psychology, 24(1), 31-40. https://doi.org/10.1207/s15374424jccp2401_4.

Bandalos, D. (2002). The effects of item parceling on goodness-offit and parameter estimate bias in structural equation modeling. Structural Equation Modeling, 9, 78-102. https://doi.org/10.1207/ S15328007SEM0901_5.

Britt, S. L., Hill, E. J., LeBaron, A. B., Lawson, D. R., \& Bean, R. A. (2017). Tightwads and spenders: Predicting financial conflict in couple relationships. Journal of Financial Planning, 30(5), 36-42.

Brown, S. L., \& Kawamura, S. (2010). Relationship quality among cohabitors and marrieds in older adulthood. Social Science Research, 39, 777-786. https://doi.org/10.1016/j.ssresearch .2010.04.010.

Bryant, C. M., \& Conger, R. D. (1999). Marital success and domains of social support in long-term relationships: Does the influence of network members ever end? Journal of Marriage and the Family, 61, 437-450. https://doi.org/10.2307/353760.

Campbell, C. L., \& Demi, A. S. (2000). Adult children of fathers missing in action (MIA): An examination of emotional distress, grief, and family hardiness. Family Relations, 49(3), 267-276. https:// doi.org/10.1111/j.1741-3729.2000.00267.x.

Cohen, J. (1992). A power primer. Psychological Bulletin, 112, 155159. https://doi.org/10.1037/0033-2909.112.1.155.

Cohen, S., \& Wills, T. A. (1985). Stress, social support, and the buffering hypothesis. Psychological Bulletin, 98(2), 310. https://doi. org/10.1037/0033-2909.98.2.310.

Cox, M. J., \& Paley, B. (2003). Understanding families as systems. Current Directions in Psychological Science, 12, 193-196. https ://doi.org/10.1111/1467-8721.01259.

Curran, M. A., McDaniel, B. T., Pollitt, A. M., \& Totenhagen, C. J. (2015). Gender, emotion work, and relationship quality: A daily diary study. Sex Roles, 73, 157-173. https://doi.org/10.1007/s1119 9-015-0495-8

Curran, M. A., Parrott, E., Ahn, S., Serido, J., \& Shim, S. (2018). Young adults' life outcomes: Perceived financial influences from parents, the romantic partner, and young adults' own financial behaviors. Journal of Family and Economic Issues, 39, 445-456. https://doi.org/10.1007/s10834-018-9572-9.

Dew, J. P. (2007). Two sides of the same coin? The differing roles of assets and consumer debt in marriage. Journal of Family and Economic Issues, 28, 89-104. https://doi.org/10.1007/s 1083 4-006-9051-6.

Dew, J. (2009). The gendered meanings of assets for divorce. Journal of Family and Economic Issues, 30(1), 20-31. https://doi. org/10.1007/s10834-008-9138-3.

Dew, J. P., Anderson, B. L., Skogrand, L., \& Chaney, C. (2017). Financial issues in strong African American marriages: A strengthsbased, qualitative approach. Family Relations, 66, 287-301. https ://doi.org/10.1111/fare.12248.

Dew, J. P., LeBaron, A. B., \& Allsop, D. B. (2018). Can stress build relationships? Predictors of increased marital commitment resulting from the 2007-2009 recession. Journal of Family and Economic Issues, 39(3), 405-421. https://doi.org/10.1007/s1083 4-018-9566-7.

Enders, C. K. (2010). Applied missing data analysis. New York: The Guilford Press.

Feinberg, M. E. (2003). The internal structure and ecological context of coparenting: A framework for research and intervention. Parenting: Science and Practice, 3(2), 95-131. doi:10.1207/ S15327922PAR0302_01

Fincham, F. D., Beach, S. R., Lambert, N., Stillman, T., \& Braithwaite, S. (2008). Spiritual behaviors and relationship satisfaction:
A critical analysis of the role of prayer. Journal of Social and Clinical Psychology, 27(4), 362-388. https://doi.org/10.1521/ jscp.2008.27.4.362.

Furstenberg, F. F. (2014). Fifty years of family change: From consensus to complexity. Annals of the American Academy of Political and Social Science, 654(1), 12-30. https://doi.org/10.1177/00027 16214524521.

Greenfield, P. M. (2017). Cultural change over time: Why replicability should not be the gold standard in psychological science. Perspectives on Psychological Science, 12(5), 762-771. https://doi. org/10.1177/1745691617707314.

Guzzo, K. B. (2014). New partners, more kids: Multiple-partner fertility in the United States. The ANNALS of the American Academy of Political and Social Science, 654(1), 66-86. https://doi. org/10.1177/0002716214525571.

Harknett, K. (2008). Mate availability and unmarried parent relationships. Demography, 45(3), 555-571. https://doi.org/10.1353/ dem.0.0012.

Hill, E., Allsop, D. B., LeBaron, A. B., \& Bean, R. A. (2017). How do money, sex, and stress influence marital instability? Journal of Financial Therapy, 8(1), 21-42. https://doi. org/10.4148/1944-9771.1135.

Jamison, T. B., Ganong, L., \& Proulx, C. M. (2017). Unmarried coparenting in the context of poverty: Understanding the relationship between stress, family resource management, and resilience. Journal of Family and Economic Issues, 38(3), 439-452. https://doi. org/10.1007/s10834-016-9518-z.

Kapp, L., \& Brown, O. (2011). Resilience in families adapting to autism spectrum disorder. Journal of Psychology in Africa, 21(3), 459-463. https://doi.org/10.1080/14330237.2011.10820482.

Kelley, H. H., LeBaron, A. B., \& Hill, E. J. (2018). Financial stress and marital quality: The moderating influence of couple communication. Journal of Financial Therapy, 9(2), 18-36. https://doi. org/10.4148/1944-9771.1176.

Kenny, D. A., Kashy, D. A., \& Cook, W. L. (2006). Dyadic data analysis. New York, NY: Guilford Press.

Kline, R. B. (2015). Principles and practice of structural equation modeling (4th ed.). New York, NY: The Guildford Press.

Le, B., \& Agnew, C. (2003). Commitment and its theorized determinants: A meta-analysis of the investment model. Personal Relationships, 10, 37-57.

LeBaron, A. B., Holmes, E. K., Yorgason, J. B., Hill, E. J., \& Allsop, D. B. (2019). Feminism and couple finance: Power as a mediator between financial processes and relationship outcomes. Sex Roles, 81(3), 140-156. https://doi.org/10.1007/s11199-018-0986-5.

Little, T. D. (2013). Longitudinal structural equation modeling. New York: The Guildford Press.

Lundberg, S., Pollak, R. A., \& Stearns, J. (2016). Family inequality: Diverging patterns in marriage, cohabitation, and childbearing. Journal of Economic Perspectives, 30, 79-102. https://doi. org/10.1257/jep.30.2.79.

MacCallum, R. C., \& Austin, J. T. (2000). Applications of structural equation modeling in psychological research. Annual Review of Psychology, 51, 201-226. https://doi.org/10.1146/annurev.psych .51.1.201.

Marks, L. D., Dollahite, D. C., \& Baumgartner, J. (2010). In God we trust: Qualitative findings on finances, family, and faith from a diverse sample. Family Relations, 59, 439-452. https://doi.org/1 0.1111/j.1741-3729.2010.00614.x.

Patterson, J. M. (1988). Families experiencing stress: I. The family adjustment and adaptation response model: II. Applying the FAAR model to health-related issues for intervention and research. Family Systems Medicine, 6(2), 202-237. doi:10.1037/ h0089739.

Pedro, M. F., Ribeiro, T., \& Shelton, K. H. (2012). Marital satisfaction and partners' parenting practices: The mediating role of 
coparenting behavior. Journal of Family Psychology, 26, 509-522. https://doi.org/10.1037/a0029121.

Prawitz, A. D., Kalkowski, J. C., \& Cohart, J. (2013). Responses to economic pressure by low-income families: Financial distress and hopefulness. Journal of Family and Economic Issues, 34(1), 29-40. https://doi.org/10.1007/s10834-012-9288-1.

Serido, J., Curran, M., Wilmarth, M., Ahn, S., Shim, S., \& Ballard, J. (2015). The unique role of parents and romantic partners on young adults' financial attitudes and behaviors. Family Relations, 64, 696-710. https://doi.org/10.1111/fare.12164.

Shapiro, M. (2007). Money: A therapeutic tool for couples therapy. Family Process, 46, 279-291. https://doi.org/10.111 1/j.1545-5300.2007.00211.x.

Skogrand, L., Johnson, A. C., Horrocks, A. M., \& DeFrain, J. (2011). Financial management practices of couples with great marriages. Journal of Family and Economic Issues, 32, 27-35. https://doi. org/10.1007/s10834-010-9195-2.

Stanley, S. M., \& Markman, H. J. (1992). Assessing commitment in personal relationships. Journal of Marriage and Family, 54(3), 595-608. https://doi.org/10.2307/353245.

Stanley, S. M., Markman, H. J., \& Whitton, S. W. (2002). Communication, conflict, and commitment: Insights on the foundations of relationship success from a national survey. Family Process, 41, 659-675. https://doi.org/10.1111/j.1545-5300.2002.00659.x.

Totenhagen, C. J., Wilmarth, M. J., Serido, J., Curran, M. A., \& Shim, S. (2020). Pathways from financial knowledge to relationship satisfaction: The roles of financial behaviors, perceived shared financial values with the romantic partner, and debt. Journal of Family and Economic Issues, Advanced online publication. https ://doi.org/10.1007/s10834-019-09611-9

United States Census Bureau. (2017). Educational attainment-People 25 years old and over by median income and sex. Retrieved from https://www.census.gov/data/tables/time-series/demo/incom e-poverty/historical-income-people.html

Waller, M. R. (2012). Cooperation, conflict, or disengagement? Coparenting styles and father involvement in fragile families. Family Process, 51(3), 325-342.

Wilcox, W. B., \& Dew, J. P. (2016). The social and cultural predictors of generosity in marriage: Gender egalitarianism, religiosity, and familism. Journal of Family Issues, 37, 97-118. https://doi. org/10.1177/01925.

Wood, R. G., McConnell, S., Moore, Q., Clarkwest, A., \& Hsueh, J. (2012). The effects of building strong families: A healthy marriage and relationship skills education program for unmarried parents. Journal of Policy Analysis and Management, 31(2), 228-325.

Publisher's Note Springer Nature remains neutral with regard to jurisdictional claims in published maps and institutional affiliations.
Ashley B. LeBaron is a doctoral student in Family Studies and Human Development at the University of Arizona. Her research focus is family finance, including couple finance and financial socialization. Ashley was valedictorian for the College of Family, Home, and Social Sciences at Brigham Young University in 2016, Graduate Student of the Year for the Utah Council on Family Relations (UTCFR) in 2018, and Best Family Economics Student Researcher for the National Council on Family Relations (NCFR) Family Economics Focus Group in 2019.

Melissa A. Curran is an Associate Professor in Family Studies and Human Development at the University of Arizona. In her scholarly work, she examines how finances are connected to individuals, couples, and families as well as how constructs such as relational sacrifices are associated with relationship quality for romantic dyads. She earned her Ph.D. in Human Development and Family Sciences from the University of Texas at Austin.

Xiaomin Li, M. Ed., doctoral student of Department of Family Studies and Human Development at University of Arizona. Her research focus is to identify the process and factors that promote well-being for couples and individuals in stressful conditions.

Dr. Jeffrey P. Dew is an Associate Professor in the School of Family Life at Brigham Young University. He teaches family theory and family finance courses at BYU. Dr. Dew's research focuses on the "daily life" issue of the association between family resources (i.e., money and time) and relationship quality. Examples of Jeff's recent projects include examining factors that protect couples' marital quality during financial difficulties, and a qualitative strengths-based analysis of how African American couples talk about the role of finances in their marriage.

Trevor K. Sharp is a financial planner at Deseret Mutual Benefit Association (DMBA). He received his education from Utah Valley University's nationally ranked Personal Financial Planning Program. He likes helping people with retirement planning and running future projections but his true passion is financial coaching (helping with debt, savings, behavioral change, and especially spending plans (budgets).

Melissa A. Barnett is an Associate Professor in Family Studies \& Human Development and the Norton Endowed Chair in Fathers, Parenting and Families in the Norton School of Family \& Consumer Sciences at the University of Arizona. The goal of her program of research is to identify strengths and sources of resilience among young children and their caregivers from economically disadvantaged and other marginalized communities. She earned her Ph.D. in psychology from the University of North Carolina - Chapel Hill. 